\title{
PRONUNCIAMIENTOS OFICIALES SOBRE DOCUMENTACIÓN FÍLMICA
}

\author{
Rubén Domínguez-Delgado* \\ Facultad de Comunicación. Universidad de Sevilla. \\ María-Ángeles López-Hernández ${ }^{* *}$ \\ Facultad de Comunicación. Universidad de Sevilla.
}

\begin{abstract}
Resumen: Se hace un recorrido histórico por las diversas intervenciones de los organismos públicos internacionales, especialmente europeos, en el ámbito de la documentación fílmica, desde la gestación, durante la década de los años setenta del siglo XX, de las Recomendaciones para la Salvaguarda y Conservación de las Imágenes en Movimiento publicadas por la Unesco en 1980 hasta la actualidad. En los dictámenes fijados por estos organismos oficiales se abordan diferentes asuntos de interés relacionados con la preservación, gestión documental y accesibilidad del patrimonio cinematográfico.

Palabras clave: Documentación fílmica; documentación cinematográfica; documentación audiovisual; filmotecas; archivos filmicos; patrimonio cinematográfico; recomendaciones oficiales; normativas oficiales; disposiciones oficiales; Unesco; Parlamento Europeo; Comisión Europea.
\end{abstract}

Title: OFFICIAL PRONOUNCEMENTS ABOUT FILM LIBRARIANSHIP.

Abstract: A historical journey is made through the various interventions of international public organizations, especially European, in the field of film librarianship, from the gestation, during the decade of the seventies of the twentieth century, of the Recommendations for the Safeguarding and Conservation of the Moving Images published by Unesco in 1980 to the present. In the dispositions dictated by these official organizations different matters of interest related to the preservation, treatment and accessibility of the film heritage are approached.

Keywords: Film librarianship; audiovisual librarianship; film archives; film heritage; official provisions; official recommendations; Unesco; European Parliament; European Commission.

Copyright: (C) 2020 Servicio de Publicaciones de la Universidad de Murcia (Spain). Este es un artículo de acceso abierto distribuido bajo los términos de la licencia Creative Commons Reconocimiento 4.0 Internacional (CC BY 4.0).

\section{INTRODUCCIÓN}

Las Recomendaciones para la Salvaguarda y Conservación de las Imágenes en Movimiento, dictadas por la Unesco en 1980, supusieron un hito importante en la documentación fílmica al reconocerse mundialmente de forma "oficial", por primera vez, el valor patrimonial de los documentos fílmicos (audiovisuales, en general), los cuales existían ya desde finales del siglo XIX, pidiéndose además a los Estados actuar para salvaguardarlos.

En los últimos años, se han publicado en el ámbito de la documentación audiovisual estudios científicos con diversos enfoques, tanto históricos como técnicos, sobre los documentos fílmicos (Domínguez-Delgado, R. y LópezHernández, M.A., 2016a, 2016b, 2016c, 2017a y 2017b). No obstante, no existen hasta la fecha estudios específicos que aborden la documentación fílmica estrictamente desde el prisma oficial de los organismos públicos internacionales, pese a constituirse ellos, ineludiblemente, como una parte muy importante de la historia de la documentación audiovisual.

\section{OBJETIVO Y METODOLOGÍA}

Dado el vacío bibliográfico que existe al respecto y la importancia que, para quienes nos dedicamos a investigar la Documentación fílmica, tiene el conocer los numerosos dictámenes que rigen nuestro ámbito, hemos considerado conveniente plantearnos, como principal objetivo, el recopilar y analizar en un estudio histórico los pronunciamientos (recomendaciones, preceptos, disposiciones, informes, etc.) que, en materia de preservación, gestión documental y difusión de las imágenes en movimientos, han redactado distintos organismos internacionales, ante todo europeos, como la UNESCO, el Parlamento Europeo, el Consejo de Europa o la Comisión Europea.

\footnotetext{
*rdd@us.es

**alhernan@us.es
}

Recibido: 06-06-2019; $2^{\text {a }}$ versión: 08-01-2020; aceptado: 16-01-2020.

DOMÍNGUEZ DELGADO, R. y LÓPEZ HERNÁNDEZ, M.A. Pronunciamientos oficiales sobre documentación fílmica. Anales de Documentación, 2020, vol. 23, nº 1. Disponible en: http://dx.doi.org/10.6018/analesdoc.382841. 
Conviene aclarar que, en esta ocasión, decidimos no tratar particularmente las regulaciones nacionales, entre otras la española, por resultar todo este material inabarcable en un solo trabajo.

En cuanto a la metodología aplicada, consideramos que para llevar a buen puerto nuestro objetivo, la mejor fórmula era, sin duda, el método de análisis cualitativo, propio de las Ciencias Sociales, consistente en un estudio diacrónico profundo de todas las directrices que los organismos internacionales citados habían fijado a lo largo de casi cincuenta años de historia.

Así pues, abarcamos, en el presente estudio, desde la gestación de las Recomendaciones para la Salvaguarda y Conservación de las Imágenes en Movimiento de la Unesco (que vieron finalmente la luz en 1980) hasta la actualidad, haciendo un recorrido por todos los dictámenes que se han sucedido en lo referente al cine como patrimonio de los pueblos y, en particular, en lo relativo a la adecuada selección, gestión documental, preservación y difusión de los documentos fílmicos.

\section{ANTECEDENTES: LOS PRIMEROS MOVIMIENTOS “OFICIALES” EN POS DE LA SALVAGUARDA DE LOS DOCUMENTOS FÍLMICOS}

Con anterioridad a ese punto de inflexión que supusieron las recomendaciones de la Unesco de 1980, se produjeron ya durante la década de los años setenta del siglo XX una serie de encuentros y medidas que fueron abonando el terreno para la gestación de aquellas. Así, en 1972, el Consejo Internacional de Archivos ya había reconocido los documentos audiovisuales en un informe titulado "Archivos de las películas cinematográficas, los documentos fotográficos y las grabaciones sonoras”, preparado por Wolfgang Kohte para el VII Congreso de Moscú de dicho Consejo (Kohte, 1972).

Además, la Unesco, a través de su Consejo Internacional de Cine y Televisión, había venido estableciendo vínculos durante los setenta con un grupo de trabajo especializado en los registros audiovisuales creado por el Consejo Internacional de Archivos, así como con otras organizaciones internacionales no gubernamentales relacionadas con la materia.

Fueron la antigua Alemania Oriental y Suiza quienes solicitaron a la Unesco que pusiese los medios a su alcance para impedir la pérdida y el deterioro de tan importante patrimonio mundial (Hernández Pérez, 1992, p. 60). Y esta primera petición obtendría una respuesta positiva en la $18^{\mathrm{a}}$ reunión de la Conferencia General de dicho organismo, en 1974, en la que se adoptará la resolución 3.422, que insta a su director general a que examine la situación preocupante en la que se encuentra la conservación de los documentos audiovisuales y que intervenga de inmediato. En el texto, que comienza asumiendo ya que "las imágenes en movimiento son uno de los elementos más característicos de la creación cultural actual y de la comunicación contemporánea", así como previendo que "la capacidad de este medio para impartir conocimientos culturales, estéticos, científicos, sociales e históricos aumentará en importancia en el porvenir", se afirma que "los esfuerzos que han realizado, desde hace muchos años, los particulares, las agrupaciones, las cinematecas y los museos para salvar y conservar las imágenes en movimiento" no han sido suficientes para "impedir la desaparición de documentos valiosos que pertenecían al patrimonio cultural de la humanidad", por lo que “conviene, mediante la realización de estudios previos, buscar los medios más adecuados para suprimir los obstáculos que hasta ahora se han opuesto a ello" (Unesco, 1975, p. 59).

Y, para ello, se pide al director general la elaboración de un programa con el fin de salvaguardar estos documentos, para el que sugieren dos líneas básicas: por un lado, llevar a cabo, con las organizaciones no gubernamentales e intergubernamentales competentes, estudios sobre el problema; y, por otro lado, "estudiar la posibilidad de crear un instrumento destinado a proteger las imágenes en movimiento de la destrucción". Además, se pide también que se recomiende a los Estados miembros "que tomen desde ahora disposiciones de carácter jurídico y técnico, o si procede, que las refuercen, con el propósito de salvar y conservar las imágenes en movimiento de valor” (Unesco, 1975, p. 59).

En septiembre de 1975, un comité de expertos se reúne en Berlín, a instancias de dicho organismo, con el fin de definir los principios generales de una recomendación para la conservación de estas imágenes. Esta y otras reuniones seguirán sucediéndose en esa hilera de semillas que hacía intuir que algo importante en la materia se estaba sembrando. Así, en noviembre de 1977, se celebra en Belgrado una nueva reunión con carácter de consulta informal sobre la salvaguardia y conservación de los documentos fílmicos. En octubre de 1978, tiene lugar en Buenos Aires la importante "Reunión internacional de expertos sobre los requisitos especiales concernientes a la preservación de 
filmes y otros medios audiovisuales en países en desarrollo", convocada por la Unesco en cumplimiento de la citada resolución 3.422 (aprobada cuatro años antes) y planificada en colaboración con organizaciones internacionales como el Consejo Internacional de Cine y Televisión, la Federación Internacional de Asociaciones de Productores Cinematográficos, el Consejo Internacional de Museos, el Consejo Internacional de Archivos y la FIAF (Federación Internacional de Archivos Fílmicos).

En esta reunión se llevaron a cabo ponencias e intercambios de impresiones focalizados en problemas relativos a la conservación de los documentos fílmicos, sus aspectos legales, la catalogación, el intercambio, el acceso, la proyección, la investigación, la utilización de este tipo de documentos conservados en archivos especiales y la creación de archivos nacionales y regionales de documentos fílmicos (Unesco, 1979, p. 1). Pero estos problemas no solo se daban en los países en desarrollo, reconociéndose que "en la mayoría de los países no se había concedido a los archivos y a los archivistas que tienen que ver con las imágenes filmadas la importancia profesional que merecían" (1979, p. 3).

Además de la concienciación - "debería considerarse ilegal el hecho de destruir este tipo de testimonio del pasado" (1979, p. 3) -, se consideró crucial un reconocimiento de la función de la filmoteca y una política de archivos, ya que había muchos países que carecían aún de servicios de archivos (sobre todo aquellos en desarrollo) y, cuando contaban con colecciones, su conservación no correspondía a lo dispuesto en la materia (1979, p. 3). También se argumentaron otros problemas de los archivos de tipo técnico (personal poco cualificado por la ausencia de formación al respecto o problemas de catalogación y de programación de las proyecciones públicas) y de tipo político y legal (los cambios de régimen, la censura o los procedimientos arancelarios), "obstáculos que pueden desorganizar el funcionamiento eficaz de cualquier organización encargada de archivos" (1979, p. 6).

Posteriormente, y tras reconocerse que "empezar en este momento a realizar un esfuerzo internacional concertado con miras a preservar los registros de imágenes filmadas es empezar muy tarde" $(1979$, p. 6), se enumeraron veintiuna precisas recomendaciones, con sus respectivas instrucciones de ejecución, que podemos resumir básicamente en apoyo moral, financiero y técnico: convocando y presidiendo reuniones de especialistas en la materia; apoyando conferencias internacionales (como el congreso anual de la FIAF, ya creada en 1938); elaborando un registro internacional de documentos fílmicos; publicando y difundiendo manuales para los archivos con el fin de que estos "se ajusten a todo tipo de condiciones climáticas y a las necesidades de los usuarios"; llevando a cabo una mayor investigación; proporcionando formación especializada en una titulación propia, entre otras acciones. Además, se enumeran hasta otras once sugerencias para que la Unesco haga llegar a sus Estados miembros, como, sobre todo, reconocer la labor de las filmotecas como una cuestión cultural y científica, reconocer el carácter profesional de estos archivos y sus archivadores, o "fomentar la catalogación de material de imágenes filmadas de acuerdo con criterios que, entre otras cosas, faciliten la lógica recuperación de elementos con cualquier propósito" (1979, p. 6).

En todas las reuniones que se van sucediendo durante los años setenta, se generan algunos debates que se centran también en los conflictos de intereses entre los representantes de las asociaciones de productores y las organizaciones de derechos de autor, por un lado, y los especialistas en filmotecas, por otro, llegándose a un compromiso de acuerdo por el que autores y productores admiten la necesidad del depósito legal y los responsables de los archivos aceptan que las copias de los documentos sean depositadas en las instituciones nacionales dedicadas a tal fin, dejando, con ello, de estar dispersas en las cinematecas y en las colecciones privadas. Este acuerdo, junto con otros relativos a las otras cuestiones y peticiones recopiladas en los sucesivos encuentros, supondrán la adopción en 1980 por parte de la Unesco, ya plasmada sobre el papel y con un carácter (solo) relativamente vinculante a nivel internacional, de las Recomendaciones para la Salvaguarda y Conservación de las Imágenes en Movimiento. No obstante, no podemos pasar por alto antes el hecho de que el Consejo de Europa había emitido ya un año antes una Recomendación sobre el Cine y el Estado (Consejo de Europa, 1979) en la que invitaba a los Estados miembros de dicho Consejo a "organizar el almacenamiento, la conservación y la restauración de películas" (Kofler, 1993, p. 72), suponiendo este texto por tanto, aunque solo a nivel europeo, el verdadero primer reconocimiento oficial de nuestros documentos fílmicos.

\section{LAS RECOMENDACIONES PARA LA SALVAGUARDA Y CONSERVACIÓN DE LAS IMÁGENES EN MOVIMIENTO DE 1980}

Este documento, adoptado en la vigesimoprimera reunión de la Conferencia General de la Unesco, celebrada en Belgrado el 27 de octubre de 1980, supuso el primer gran culmen de dimensión mundial a la preocupación e intervención llevada a cabo por organismos públicos oficiales durante la década anterior. Son numerosos los documentólogos audiovisuales que han considerado este texto un hito importante en la historia de la documentación audiovisual - de ahí que le dediquemos un epígrafe propio en nuestro recorrido histórico. 
Se trata de un documento de seis páginas estructurado en cinco bloques - considerandos, definiciones, principios generales, medidas recomendadas y cooperación internacional - en el que, en primer lugar, cabe destacar la ampliación de las fronteras del Tercer Mundo, que habían venido preocupando y focalizando los debates durante las diversas reuniones de los años anteriores, a la totalidad de países de las Naciones Unidas, a la vez que se amplía el objeto de aplicación de las recomendaciones a imágenes en movimiento, dada la multiplicidad de los documentos audiovisuales y las probables transformaciones tecnológicas venideras (Unesco, 1980, p. 168). Estas imágenes adquirirán con estas recomendaciones un valor hasta ahora no reconocido oficialmente a escala mundial de un modo similar, como "expresión de la personalidad cultural de los pueblos y que, debido a su valor educativo, cultural, artístico, científico e histórico, forman parte integrante del patrimonio cultural de una nación”. Por ello, se advierte que "debido a la naturaleza de su soporte material y a los diversos métodos de su fijación, las imágenes en movimiento son extraordinariamente vulnerables y deberían conservarse en condiciones técnicas específicas”, denunciándose a su vez que muchas de esas imágenes "han desaparecido debido a deterioros, a accidentes o a una eliminación injustificada, lo cual constituye un empobrecimiento irreversible de ese patrimonio" (1980, p. 167).

Y se señala directamente con el dedo a los Estados, apuntándose que es "necesario que cada Estado tome medidas complementarias adecuadas encaminadas a garantizar la salvaguardia y la conservación para la posteridad de esa parte especialmente frágil de su patrimonio cultural, del mismo modo que se salvaguardan y conservan otras formas de bienes culturales como fuente de enriquecimiento para las generaciones presentes y futuras"; medidas que, a su vez, “deberían tener debidamente en cuenta la libertad de opinión, expresión e información, reconocida como parte esencial de los derechos humanos y de las libertades fundamentales inherentes a la dignidad de la persona humana, y la necesidad de reforzar la paz y la cooperación internacional, así como la posición legítima de los titulares de derechos de autor y de todos los demás derechohabientes sobre las imágenes en movimiento". Para ello, y aunque privilegie la producción nacional, ve necesaria la cooperación y solidaridad internacional entre los diferentes Estados al considerar, entre otros factores, "que las imágenes en movimiento creadas por los pueblos de todo el mundo forman parte del patrimonio de la humanidad en su conjunto" (1980, p. 167). Con estas consideraciones previas, entre otras, la Conferencia General de la Unesco:

"Recomienda a los Estados miembros que apliquen las siguientes disposiciones, adoptando, en forma de ley nacional o de otro modo, y de conformidad con el sistema o la práctica constitucional de cada Estado, las medidas necesarias para aplicar en los territorios bajo su jurisdicción los principios y normas formulados en la presente Recomendación.

\section{(...) Que pongan la presente Recomendación en conocimiento de las autoridades y servicios competentes.}

(...) Que le sometan, en las fechas y en la forma que determine, las medidas tomadas para aplicar la presente Recomendación" (1980, p. 168).

Y entre las numerosas medidas se incluyen: invitar a la creación de filmotecas en países que aún no dispongan de ellas, equipar a todos los archivos de recursos adecuados tanto humanos como materiales y económicos, difundir las filmografías o catálogos nacionales y unificar los sistemas de catalogación, otorgar prioridad a la producción nacional, cuestiones jurídicas en torno al depósito legal o la petición de que "se debería de facilitar el más amplio acceso a las obras" (1980, p. 169).

No obstante, a la aparición de este texto de la Unesco seguiría de inmediato un debate en el que se discute una contradicción que podía apreciarse en sus recomendaciones, y que hará que algunos países hagan caso omiso a este documento oficial - llegando a afirmar Raymond Borde que "el texto del 27 de octubre de 1980 finalmente tuvo pocas repercusiones" (Borde, 1991, p. 144). Y es que si se pedía a los Estados que creasen archivos para acoger el depósito legal y se limitaba este a la producción nacional, los países del Tercer Mundo, que tanto preocupaban a la Unesco y que en su mayoría carecían de producción cinematográfica propia, ¿qué protegerían en sus archivos?

No obstante, sea como fuere y visto desde la perspectiva actual, sí es cierto que se llega a una nueva etapa en la evolución de la documentación fílmica y audiovisual, ya que desde 1980, tras la concienciación pública sobre el valor de las imágenes en movimiento y el buen clima de confianza con los productores al que tanto había costado llegar, se crearán infinidad de filmotecas por decisión de los Estados y sus ministerios de cultura, muchas de ellas a nivel autonómico, provincial o local, dentro de sus programas políticos de actuación. En el caso de España, se crean desde este momento archivos autonómicos cinematográficos como la Filmoteca de Zaragoza en 1981, la Filmoteca de Catalunya en 1982, la Filmoteca Canaria en 1984, la Filmoteca de la Generalitat Valenciana en 1985, la Filmoteca de Andalucía en 1989, junto a otras posteriores ya en la década de los noventa y en el siglo XXI. Como contrapunto, cabe apuntar que aprovecharon este boom algunos archivos piratas con el objetivo de lucrarse tras el disfraz de 
conservadores del patrimonio, lo que generó un conflicto ante el que tuvo que intervenir la FIAF en su Congreso de Rapallo de 1981 con una Declaración sobre el Papel de los Archivos del Filme, en la que se aclaraban los bienintencionados objetivos de las verdaderas filmotecas (Borde, 1991, p. 153).

\section{OTRAS INTERVENCIONES INTERNACIONALES OFICIALES POSTERIORES EN MATERIA DE DOCUMENTACIÓN FÍLMICA DURANTE EL SIGLO XX}

Tras el dictado de las recomendaciones de 1980, los organismos públicos internacionales, fundamentalmente la Unesco (de nuevo), el Parlamento Europeo, el Consejo de Europa y la Comisión Europea, seguirán, en los años posteriores, preocupándose e interviniendo de forma continua en materia documental audiovisual para procurar la salvaguarda del patrimonio fílmico.

Así, otra muestra de esta concienciación llega con un nuevo texto relativo ya al proceso documental técnico al que se someten los documentos fílmicos, en concreto a su evaluación y selección. Se trata del estudio realizado por Sam Kula, en virtud de un contrato con el Consejo Internacional de Archivos (ICA), encargado y publicado en 1983 por la División del Programa General de Información de la Unesco, bajo el título "La evaluación de las imágenes en movimiento de los archivos: un estudio del RAMP (Programa de Gestión de Documentos y Archivos) con directrices" (Kula, 1983). Pretendía hacer una comparativa de las antiguas y actuales políticas en la labor documental de selección y "prestar asistencia a los archiveros y gestores de registros que se dedican a la selección de las imágenes en movimiento para su conservación" (1983, p. 1). El estudio supone para el autor, aunque llegue tarde, "otra indicación de que los depósitos de archivos tanto gubernamentales como no gubernamentales comienzan a asumir responsabilidades respecto a las imágenes en movimiento" (1983, p. 2), pero cree que ahora le llega el turno a los diferentes Estados y que "dependerá de las circunstancias de cada país” (1983, p. 12).

Un año después, en abril de 1984, la Unesco reúne en Viena a un grupo de expertos en el desarrollo de los archivos audiovisuales para que lleven a cabo una encuesta sobre el grado de aplicación de sus Recomendaciones de 1980, la cual se encomienda a la FIAF y a la FIAT (Federación Internacional de Archivos Televisivos) y cuyo informe final se presentaría al año siguiente (Unesco, 1985). También se debatieron en el encuentro cuestiones jurídicas relativas a los archivos audiovisuales (tema que se convertiría en recurrente desde entonces), expresándose el deseo de iniciar "un estudio del derecho de autor en relación con las imágenes en movimiento a fin de determinar modificaciones que permitieran el funcionamiento de los archivos de imágenes en movimiento, y paralelamente un estudio de la legislación sobre archivos para determinar si se les puede eximir de las restricciones que impone el derecho de autor" $(1985$, p. 3).

En la misma década, se sucedieron, además, otros pronunciamientos oficiales destinados principalmente a realzar el valor del patrimonio cinematográfico, como es el caso de la Recomendación sobre la Conservación del Patrimonio Cinematográfico Europeo (Consejo de Europa, 1985), en la que el Consejo europeo incluirá explícitamente a las películas en el patrimonio cultural y social, subrayando el cometido esencial que cumplen los archivos y diferenciando entre la destrucción voluntaria y las pérdidas involuntarias.

Tres años después, en 1988, la Unesco organiza una mesa redonda para evaluar los resultados prácticos de su Recomendación de 1980, volviendo a subrayarse en ella la ausencia de una legislación especializada sobre archivos audiovisuales como una cuestión de primera índole en la materia. Así, se recordó que el concepto de archivo audiovisual había sido forjado sobre todo en los últimos cuarenta años, por lo que se había avanzado poco en materia de estatutos, textos jurídicos legales y otros instrumentos políticos o administrativos destinados a definir el papel de esos archivos en el contexto nacional. E incluso se advertía que, en los tiempos que corrían (ocho años ya después del texto de 1980), en la mayoría de los países el desarrollo de archivos de imágenes en movimiento había constituido una extensión del archivo nacional que se ocupa principalmente de los documentos escritos.

Por ello, los miembros de la mesa propusieron compilar y analizar los textos jurídicos disponibles sobre la creación, el funcionamiento, el cometido, los deberes y las obligaciones de los archivos audiovisuales, incluyendo documentos y estatutos jurídicos tipo que se pudieran adaptar a las situaciones específicas de cada país. Tras esto, se elaboraría el estudio "Cuestiones jurídicas relacionadas con los archivos audiovisuales", publicado en 1991 por Birgit Kofler para la Unesco, en el que se destaca "la ausencia de legislaciones relacionadas específicamente con los problemas que plantean los archivos audiovisuales", ya que "la mayor parte de los países carecen de una legislación sobre el funcionamiento de los archivos audiovisuales o, cuando existe, es incompleta" (Kofler, 1991, p. 1). Se apunta, además, que "los instrumentos internacionales que se refieren a la preservación de las grabaciones audiovisuales (entre ellos la Recomendación de 1980), no son vinculantes y generalmente no están integrados en la legislación nacional, 
aunque la posibilidad y la conveniencia de hacerlo salten a la vista", a lo que se añade que "la situación es análoga en las legislaciones nacionales" (Kofler, 1991, p. 2). Como solución, se propone la necesidad de establecer una legislación global relativa a los archivos desde el momento en que se planifican o se crean.

Un año después, en 1992, la Unesco crea el Programa Memoria del Mundo, con el fin de minimizar las pérdidas reales o potenciales del patrimonio documental - incluyendo los filmes, entre otros muchos tipos de documentos - por medio de la preservación de las colecciones y del acervo en peligro, así como asegurar su accesibilidad. Aunque su alcance incluye diversos participantes - estudiantes, especialistas, público en general, propietarios, proveedores y productores de información y fabricantes de productos finales -, se designaría, para orientar la planificación y ejecución de sus actividades, un Comité Consultivo Internacional (CCI), el cual se reunió por primera vez en Polonia en 1993, en un encuentro en el que se preparó un plan de acción que definiría la función de la propia Unesco como coordinadora y catalizadora para sensibilizar a los gobiernos, las organizaciones internacionales y las fundaciones, así como fomentar la creación de asociaciones con miras a la ejecución de los proyectos.

Además, se inició la preparación de directrices para el programa a través de un contrato con la Federación Internacional de Asociaciones de Bibliotecarios y Bibliotecas (IFLA), así como la elaboración, por parte de esta federación y del Consejo Internacional de Archivos, de listas de colecciones de bibliotecas y de fondos de archivos que hubiesen sufrido daños irreparables. Por medio de sus comisiones nacionales, la Unesco preparó una lista de fondos documentales en peligro y otra mundial del patrimonio cinematográfico de distintos países. Al mismo tiempo, se iniciaron una serie de proyectos piloto que recurrían a las nuevas tecnologías para reproducir en otros soportes el material original del patrimonio documental, lo que mejoraría el acceso a este - aunque en mucho menor grado en el caso de los documentos fílmicos - y contribuiría a su preservación.

Desde entonces, se han venido celebrando reuniones del CCI cada dos años, además de conferencias internacionales de la Memoria del Mundo y encuentros de expertos, y se han formado nuevos comités nacionales y regionales. El Registro de la Memoria del Mundo, que en cierto modo es el aspecto del programa más visible para el público, se basa en las "Directrices para la salvaguarda del patrimonio documental” publicadas por la Unesco en 1995 por primera vez (Unesco, 1995a) y revisadas en 2002 (Edmondson, 2002), y se va ampliando a través de las inscripciones aprobadas por las sucesivas reuniones del CCI.

Por otro lado, y retomando de nuevo los pronunciamientos oficiales internacionales en el ámbito estrictamente fílmico, podemos destacar la 27 a reunión de la Conferencia General de la Unesco celebrada en París en 1993, en la que tiene lugar un llamamiento de su director general a favor de la salvaguarda del patrimonio cinematográfico internacional, considerado como "memoria del siglo XX" (Unesco, 1995b, p. 1), o la 146 a reunión del Consejo Ejecutivo de la Unesco de 1995, en la que su director presenta un reglamento financiero del fondo de la Unesco para la salvaguarda del patrimonio cinematográfico, así como los estatutos de un comité consultivo para dicha protección, todo ello como parte de la celebración del centenario del cine y "habida cuenta del enorme peligro de destrucción que corre la memoria cinematográfica del siglo XX” (1995b, p. 1). Los objetivos de este fondo, para el cual se establece una Cuenta Especial para la Salvaguardia del Patrimonio Cinematográfico, serían los siguientes: cofinanciar proyectos de restauración del patrimonio; investigaciones sobre las filmografías nacionales y regionales; formación de especialistas en los diferentes ámbitos de conservación, salvaguardia, protección y difusión del patrimonio; fomentar la compra de equipo para los centros e institutos de conservación del patrimonio; el envío de consultores o expertos para la creación o modernización de centros de archivo y de difusión del patrimonio; la creación de cinematecas o archivos nacionales y la distribución de películas restauradas.

Además, se redactan los estatutos del comité anteriormente mencionado, que se encargará de "asesorar a la Organización sobre su programa de protección, formación, investigación, intercambio de información y salvaguardia del patrimonio cinematográfico nacional, regional e internacional” (1995b, p. 4). Se reunirá en sesión ordinaria cada dos años y lo integrarán inicialmente 11 miembros (actualmente 14) nombrados por el Director General de la Unesco en consulta con la FIAF, "elegidos en función de su competencia en materia de estudios sobre salvaguardia del patrimonio cinematográfico, tomando debidamente en cuenta la distribución geográfica y con miras a representar las diversas disciplinas y las distintas corrientes de pensamiento existente sobre el tema en los Estados miembros" (1995b, p. 4).

También en 1995, como parte del Programa Memoria del Mundo y en reconocimiento del impacto del cine, se decidió compilar y publicar una lista de aproximadamente quince documentos fílmicos considerados por cada país como parte integral de su patrimonio fílmico nacional más significativo, basada en criterios como la importancia histórica o el valor cultural y artístico (Unesco, 1995c, p. 6). 
Por otro lado, se ha venido desarrollando desde mediados de los años ochenta del pasado siglo una política de fomento de la industria audiovisual europea, con el fin de reforzar la capacidad audiovisual de Europa y lograr un mayor reflejo de la riqueza y la diversidad de la cultura europea en los distintos medios audiovisuales. Con este fin principal, el Parlamento Europeo y el Consejo Europeo han venido interviniendo desde entonces en materia de archivos audiovisuales. Así, se aprueba en 1990 el programa MEDIA de fomento de la industria audiovisual europea, para un período de cinco años (1991-1995) y con el que se pretendía, entre otros fines, "la contribución a la creación de un segundo mercado, en especial a partir del aprovechamiento de los archivos" (Consejo de Europa, 1990, p. 37). En este programa se recogen acciones concretas en materia documental, tales como: prestar apoyo al funcionamiento y al fortalecimiento del MAP-TV (red de servicios de archivos europeos); aprovechar esta memoria colectiva así como el patrimonio cinematográfico y televisual europeo mediante la conservación, restauración, reedición y nueva difusión de obras o mediante la utilización de extractos para la producción de nuevos programas; buscar y experimentar soluciones a los problemas de los derechos que obstaculizan la utilización de los archivos; o, por último, elaborar catálogos que contribuyan a promocionar los archivos.

Con el programa MEDIA nacerán, además, en 1991, la Asociación de Filmotecas Europeas - ACCE o Association of Filmarchives of the European Community inicialmente y, desde 1995, ACE o Association des Cinémathèques Européennes, que cuenta en la actualidad con 44 miembros - y el proyecto LUMIÈRE, el cual velaría (hasta 1995 , cuando concluye) por: la conservación y restauración de documentos fílmicos europeos, la búsqueda de documentos fílmicos europeos perdidos o la creación de una base de datos filmográfica de todas las películas producidas en Europa desde 1895 .

El programa MEDIA tendría su continuidad con la aprobación en 1995 de MEDIA II, para el periodo 1996-2000, y este, a su vez, con MEDIA PLUS 2001-2006 - en el que se hace referencia a la necesidad de "digitalizar e interconectar los catálogos (...) incluyendo los archivos y el patrimonio cinematográfico” (Consejo de Europa, 2000b, p. 84) -, MEDIA 2007 - para el periodo 2007-2013 y en el que se recomienda "tener en cuenta, desde un primer momento, las tecnologías digitales para la producción, la posproducción, la distribución, la comercialización y el archivo" (Parlamento Europeo y Consejo Europeo, 2006, p. 20), pidiéndose para ello reforzar la formación a todos los niveles - y el actual subprograma MEDIA, enmarcado dentro del nuevo programa cultural más amplio Europa Creativa, aprobado en 2013 para el periodo 2014-2020, que incluye a los archivos como parte del sector cultural y creativo y que recoge entre sus objetivos la salvaguarda y promoción del patrimonio documental (Parlamento Europeo y Consejo Europeo, 2013, p. 225-226).

Además, se trabaja actualmente en el siguiente plan del programa para el periodo 2021-2028, habiéndose publicado ya una primera propuesta que recoge entre sus principales prioridades "ofrecer un acceso más amplio a nivel transfronterizo a las obras audiovisuales europeas, en particular a través de modelos empresariales innovadores y el uso de nuevas tecnologías" (Parlamento Europeo y Consejo de Europa, 2018, p. 25). En ella, además, se hace hincapié en la importancia de desarrollar sinergias con otros instrumentos y programas de investigación e innovación de la Unión Europea (como el vigente Horizonte 2020), ya que "la puesta en común de los recursos, con el fin de aplicar las últimas tecnologías y estimular nuevos enfoques científicos, puede mejorar considerablemente la comprensión, preservación y difusión del patrimonio cultural y beneficiar a los sectores de la cultura y la creación en general” (2018, p. 2).

\section{6 ÚLTIMOS PRONUNCIAMIENTOS OFICIALES EN EL SIGLO XXI}

El siglo XXI se inicia, en materia de dictámenes oficiales en relación con los documentos fílmicos, con una nueva Resolución del Consejo Europeo en el año 2000 relativa a la conservación y promoción del patrimonio cinematográfico europeo (Consejo de Europa, 2000a). En ella, se insta a los Estados miembros a cooperar en la restauración y conservación del patrimonio cinematográfico, incluido el recurso a las técnicas de digitalización proceso este último que se constituirá desde entonces en uno de los principales focos de atención y preocupación por parte los archivos fílmicos -, a intercambiar las prácticas más idóneas en este ámbito, a fomentar la constitución gradual de una red de bases de datos de los archivos europeos y a estudiar la posibilidad de utilizar las colecciones con fines pedagógicos.

Además, la Comisión Europea convocaría el Programa Econtent 2001-2004 (Consejo de Europa, 2001a, p. 32-40) para estimular el desarrollo y el uso de contenidos digitales europeos (entre ellos los fílmicos), además de promover la diversidad lingüística. A este le continuaría el Programa Econtentplus 2005-2008 (Parlamento Europeo y Consejo Europeo, 2005a), que pretende atenuar la fragmentación del mercado europeo del ámbito de los contenidos digitales y 
mejorar la accesibilidad y la facilidad de utilización de la información geográfica, el material educativo y los contenidos culturales en general, para facilitar la creación y difusión de información en toda la Unión Europea.

Por otro lado, la Comisión Europea examinaría también en 2001 la cuestión del depósito legal de los documentos fímicos (especialmente) y audiovisuales, a escala nacional o regional, como una de las posibles maneras de conservar y proteger este patrimonio europeo - dada la reconocida falta de consenso al respecto -, así como la creación de un registro europeo (o la interconexión de los registros nacionales) y otras posibles modalidades y usos de bases de datos (Comisión Europea, 2001, p. 11-16). Ese mismo año se llega a un acuerdo en el Consejo Cultura/Audiovisual de 5 de noviembre de 2001, estableciéndose en el convenio europeo que "cada parte ha de imponer el depósito legal obligatorio del material de imágenes en movimiento que forma parte de su patrimonio audiovisual producido o coproducido en su territorio" (Consejo Europeo, 2001b, p. 2).

En 2002, el Parlamento Europeo manifestó su apoyo a este convenio y pidió a la comisión y al consejo la creación de un instrumento destinado a la cofinanciación de los trabajos de digitalización de estos archivos (Parlamento Europeo y Consejo Europeo, 2003, p. 178). Tres años después, insistiría con este último aspecto, pronosticando que "el paso gradual a las tecnologías digitales permitirá una mayor competitividad de la industria cinematográfica europea y contribuirá, a largo plazo, a reducir los costes de catalogación, depósito, conservación y restauración de las obras audiovisuales. Al mismo tiempo, creará nuevas oportunidades de innovación en el ámbito de la protección del patrimonio cinematográfico" (Parlamento Europeo y Consejo Europeo, 2005a, p. 2).

También en 2005, otra recomendación del Parlamento y del Consejo europeos trata de "promover una mejor explotación del potencial industrial y cultural del patrimonio cinematográfico europeo mediante el fomento de las políticas de innovación, investigación y desarrollo tecnológico en el ámbito de la conservación y restauración de obras cinematográficas", contemplándose la labor que realizan las filmotecas como vital para el fortalecimiento de la industria cinematográfica europea (Parlamento Europeo y Consejo Europeo, 2005b, p. 1). Y se insiste en que, cuando se alude a esta industria, "no es aplicable solo a la producción y proyección de películas, sino también a la recopilación, catalogación, conservación y restauración de obras cinematográficas”, advirtiéndose que las condiciones "deben mejorarse, especialmente en lo que se refiere a un mejor uso de los progresos tecnológicos, como la digitalización" (2005b, p. 2). Además, en el texto se le atribuyen valores culturales importantes al documento fílmico (2005b, p. 1) y se reconoce que la intervención de los poderes públicos se antoja fundamental para preservar este patrimonio, proponiéndose "la adopción (...) de medidas legislativas, administrativas u otras adecuadas, que garanticen que las obras cinematográficas que formen parte de su patrimonio audiovisual sean sistemáticamente recogidas, catalogadas, conservadas y restauradas, de forma que estén accesibles para usos pedagógicos, culturales y de investigación, así como otros usos similares no comerciales, respetando en todos los casos los derechos de autor y derechos afines", además de "la designación de organismos idóneos encargados de llevar a cabo las tareas de interés público descritas, con independencia y profesionalidad, garantizándoles los mejores recursos técnicos y económicos disponibles" (2005b, p. 3).

Este importante texto de 2005 concluye con un compendio de recomendaciones estructuradas en las diferentes etapas del proceso documental llevado a cabo por las filmotecas sobre los documentos fílmicos. Así, en cuanto a la recopilación, se recoge el depósito obligatorio de la producción nacional (incluyendo coproducciones) en las filmotecas nacionales en dos años desde el estreno y "acompañadas de metadatos en un formato normalizado" (2005b, p. 4), apuntándose la posibilidad de ampliarlo a la producción europea en al menos una filmoteca nacional de cada país - solo en el caso de aquellos filmes que reciban ayudas de la Unión Europea. También se pide estudiar la ampliación del depósito a "material publicitario y accesorio relativo a las obras cinematográficas", así como a "material de imágenes en movimiento que no sean obras cinematográficas y obras cinematográficas del pasado" (2005b, p. 5).

En lo relativo a la catalogación y creación de bases de datos, se propone promover estas dos tareas utilizando normas europeas e internacionales y elaborar un índice de obras cinematográficas depositadas. En este sentido, se recomienda "fomentar la normalización y la interoperabilidad europea de las bases de datos de filmografía y su disponibilidad para el público, por ejemplo, por internet". Otra petición es la de estudiar la posibilidad de establecer "una red de bases de datos que abarquen todo el patrimonio audiovisual europeo" o "la invitación a los organismos de archivo a valorizar las obras depositadas, organizándolas en colecciones a escala europea, por ejemplo, por tema, autor y período" (2005b, p. 4). También se hace un fuerte hincapié en el acceso a los documentos fílmicos en los archivos, como ya se había apuntado previamente, y, por último, se recomienda tanto la cooperación internacional como "fomentar una formación profesional en todos los ámbitos relativos al patrimonio cinematográfico" (2005b, p. 4).

Del mismo año son igualmente las enmiendas de la Comisión de Cultura y Educación del Parlamento Europeo para la conservación y acceso a los documentos cinematográficos (Parlamento Europeo, 2005), las cuales, si bien se centran 
más en la industria cinematográfica que en aspectos relacionados con los fines documentales, sí recogen peticiones como la de "apoyar la creación de un catálogo europeo unificado de las películas que se encuentran en las filmotecas nacionales de los 25 Estados miembros de la UE” (2005, p. 14). Para este fin se trabajó en el proyecto piloto europeo MIDAS 2006-2009 - Moving Image Database for Access and Re-use of European Film Collections -, contemplado dentro del Programa MEDIA PLUS y que culminó con el resultado de la plataforma Filmarchives Online (Deutsches Filminstitut, 2019), la cual reúne actualmente en una página web de acceso libre el catálogo de películas europeas de no-ficción, de animación y publicitarias (con sus respectivas fichas técnicas y la posibilidad de visualizar muchas de ellas), de hasta 18 filmotecas de la Unión Europea (ninguna española por el momento), coordinadas por la alemana Deutsches Filminstitut.

Por otro lado, en la $33^{\mathrm{a}}$ reunión de la Conferencia General de la Unesco, celebrada en octubre de 2005, los Estados miembros decidieron, como conmemoración del vigesimoquinto aniversario de la aprobación por parte de la Unesco de las Recomendaciones de 1980, proclamar el 27 de octubre Día Mundial del Patrimonio Audiovisual, “considerando que el patrimonio audiovisual puede desempeñar un papel positivo en la mejora del conocimiento mutuo de las naciones y las comunidades y contribuir ampliamente a la educación y al enriquecimiento de todos los seres humanos" (Unesco, 2005, p. 119).

Desde 2008, y de forma bianual, la Comisión Europea elaboraría un informe acerca del cumplimiento de la Recomendación de 2005, anteriormente comentada, previo envío de un cuestionario a los archivos cinematográficos de los Estados miembros. Entre los resultados del primero, publicado en 2008 (Comisión Europea, 2008c), se recoge que la mayoría de las filmotecas europeas siguen las reglas de catalogación dictadas en 1991 por la FIAF (FIAF, 1998) y tienen bases de datos electrónicas, algunas de ellas total o parcialmente disponibles en internet para los usuarios, aunque no en el caso español en aquel momento. Se apunta, además, que uno de los problemas observados es la falta de interoperabilidad entre las bases de datos, tanto a nivel europeo como incluso dentro de los mismos países, así como la falta de recursos para trabajar en este asunto. También se hace un llamamiento por parte de la comisión a aunar "todos los esfuerzos para hacer este tipo de metadatos disponibles y localizables vía internet, con vistas a la futura integración en la Biblioteca Digital Europea” (2008c, p. 7).

Nuevos informes, similares a este, se publicarán por la comisión desde entonces cada dos años, para asegurarse del cumplimiento de la Recomendación de 2005. En el de 2010, en el que se incluyen dos nuevos aspectos - los retos y oportunidades para el patrimonio cinematográfico europeo derivadas de la transición de lo analógico a lo digital y la conexión entre políticas de financiación cinematográfica y patrimonio cinematográfico - se señalan las diferencias presupuestarias entre las distintas filmotecas europeas, que oscilan entre los casi 40 millones de euros anuales que Francia destina a sus tres principales filmotecas y los no más de 500.000 euros anuales que se reparten las filmotecas de países como Irlanda, Estonia o Letonia, quedando España mal situada en dicho informe, con una inversión de poco más de 4 millones de euros destinados a su principal filmoteca nacional (Comisión Europea, 2010b, p. 28-37).

En el siguiente informe (Comisión Europea, 2012), se afirma que la mayor parte de las filmotecas europeas no se han adaptado todavía a la revolución digital, ni son capaces aún de conservar obras cinematográficas de forma digital. Además, solo el 1,5\% del patrimonio cinematográfico europeo estaba digitalizado y era accesible al público. Entre los actuales obstáculos a la digitalización se citan la escasez de financiación pública y privada y la complejidad de la compraventa de derechos, que sería larga y costosa. Por tanto, la comisión considera que los Estados deberían incluir el patrimonio cinematográfico en su estrategia de digitalización y políticas de archivo nacionales, lo que supondría un mayor contenido fílmico en Europeana. En este sentido, Neelie Kroes, vicepresidenta de la Comisión Europea, declaraba que "es ridículo que nuestro patrimonio cinematográfico no sea visible en el siglo XXI. La cultura se sitúa en el corazón de Europa y la cinematografía en el corazón de la cultura. Estoy decidida a poner en línea este legado cinematográfico y voy a presentar en 2013 una propuesta que ayude a los Estados miembros y a las partes interesadas a unir sus esfuerzos para lograr este objetivo" (Kroes, 2019).

También se alude en este informe a las diferencias en la financiación y en los recursos humanos con que cuentan las alrededor de cien filmotecas europeas existentes según el texto (Comisión Europea, 2012, p. 5), con oscilaciones entre los 300 trabajadores que se contabilizan en la principal filmoteca de Francia y los menos de 10 en la de Grecia o Irlanda, quedando España deficientemente representada, en una posición intermedia, con unos 106 trabajadores contabilizados en su principal filmoteca nacional (2012, p. 27-39). Este dato negativo encuentra correspondencia con la denuncia que hace De Fontecha (2014) acerca del drástico recorte en el presupuesto que España destina a sus filmotecas y también con su mala posición en el informe europeo con respecto a este último criterio económico (Comisión Europea, 2012, p. 27-39). 
Además, se recogen las diferentes concepciones que la noción patrimonio cinematográfico tiene para cada uno de los estados europeos. Así, mientras que algunos países (como Francia o Portugal, entre otros) incluyen en su definición el material audiovisual no cinematográfico (por ejemplo, el televisivo o los videos domésticos), otros, como es el caso de España, lo limitan exclusivamente a los "trabajos cinematográficos relacionados, a través de la producción, materia o autoría, al territorio español o cultura española en el contexto de la promoción de la identidad del país y la diversidad cultural" (Comisión Europea, 2012, p. 54).

También se apunta en el completo informe que, si tradicionalmente el rol asignado a las filmotecas era el de la preservación del patrimonio cinematográfico, en los últimos años las filmotecas han venido incrementando sus esfuerzos para facilitar además el acceso a sus colecciones, hasta el punto de que el británico British Film Institute recoge en su última política de colecciones, la cual data de noviembre de 2011, que "la preservación y el acceso tienen idéntica prioridad como objetivos" (British Film Institute, 2011).

Por último, el texto hace alusión también a la gran acogida de las normas europeas sobre metadatos para facilitar la interoperabilidad entre las bases de datos de cine, elaboradas por el Comité Europeo de Normalización (CEN), siguiendo un mandato de la Comisión Europea, en 2009 y 2010: la norma EN 15744:2009 Film Identification Minimum metadata set for cinematographic Works y la norma EN 15907:2010 Film Identification - Enhancing interoperability of metadata - Element sets and structures, respectivamente. Se considera que estas "deben implementarse ampliamente ya que serían claves para la preservación a largo plazo y el acceso a las colecciones" (Comisión Europea, 2012, p. 10), y han hecho posibles proyectos como European Film Gateway o Portal de Cine Europeo (AA.VV., 2019b), iniciado en otoño de 2008, dentro del Programa eContentplus (2004-2008), por la Asociación de las Cinematecas Europeas y la Fundación Europeana, o el posterior EFG 1914 (AA.VV., 2019c), que continuó al anterior y sigue vigente hoy, con 21 filmotecas contribuyentes, dos de ellas españolas: la española y la valenciana. Estos proyectos dan acceso, a través de sus portales web, a miles de documentos fílmicos europeos procedentes de los archivos y países participantes.

En 2014 se publicaría un nuevo informe sobre la implementación de la Recomendación de 2005, en el que se reconoce especialmente que la complejidad y los costes de los problemas en relación con los derechos "continúan siendo un obstáculo importante para proporcionar acceso online a colecciones digitalizadas, incluso para la educación" (Comisión Europea, 2014, p. 38), pese a la mejora en el acceso online a colecciones con respecto al informe anterior. Destaca también la denuncia de que los recursos económicos y humanos destinados al patrimonio cinematográfico se habrían mantenido igual que en el informe de 2012 o habrían incluso disminuido, alertándose, además, de que solo ocho países europeos habían destinado fondos presupuestarios adicionales a tareas digitales en relación con los documentos fílmicos - sin encontrarse España entre ellos (2014, p. 37-38). Este informe constituirá el último hasta la fecha, habiéndose roto en los últimos cinco años la dinámica de elaboración y publicación de estos estudios oficiales de forma bianual.

Por otro lado, la Comisión Europea ha venido adoptando en los últimos años otras medidas como la "Recomendación sobre la digitalización y la accesibilidad online del material cultural y la preservación digital" de 2006 (Comisión Europea, 2006), con normativas complementarias a la recomendación de 2005 sobre patrimonio cinematográfico. En ella, se hace un llamamiento a los Estados a actuar en varias áreas como en el incremento de recursos dedicados a la digitalización, en asuntos sobre el copyright y en la preservación sistemática del contenido cultural en formato digital, para asegurar el acceso documental a largo plazo.

Además, el 20 de diciembre de 2007, la Comisión Europea adoptó la comunicación sobre alfabetización mediática “A European approach to media literacy in the digital environment", entendiendo por alfabetización mediática, considerada un pilar importante para la política audiovisual europea, "la habilidad para acceder a los medios, para comprender y para evaluar críticamente diferentes aspectos de los medios y sus contenidos, y para crear comunicaciones en una variedad de contextos" (Comisión Europea, 2007, p. 3).

Por otro lado, la comisión adoptó un año después otra comunicación sobre contenido creativo en línea Communication on Creative Content Online (Comisión Europea, 2008a)-, con la que se promueve el desarrollo de modelos de negocio innovadores y el despliegue de diversos servicios online transfronterizos de contenido creativos. Ese mismo año, preocupada por la no adaptación a los nuevos tiempos de la era digital, dicha comisión estableció un Grupo de Expertos en Cine Digital. Este llevó a cabo en octubre de 2009 una Consulta Pública sobre Oportunidades y Retos para el Cine Europeo en la Era Digital, basada en las opiniones de 300 profesionales del cine de distintos ámbitos, las cuales serían tenidas en cuenta para sus próximas comunicaciones y medidas. 
Y en 2010 se publica la Agenda Digital Europea (Comisión Europea, 2010a), entre cuyas áreas de acción se encuentra la promoción de la diversidad cultural y el contenido creativo, lo que incluye el apoyo al cine digital y el fortalecimiento de Europeana (AA.VV., 2019a), la biblioteca digital europea de acceso libre, inaugurada en 2008, enmarcada dentro del Programa eContentPlus y que reúne contribuciones digitalizadas de importantes instituciones culturales europeas, incluyendo entre sus diversos fondos los documentos fílmicos.

También en 2010, la Comisión Europea adoptó una comunicación sobre las oportunidades y retos para el cine europeo en la era digital, "Communication on Opportunities and Challenges for European Cinema in the Digital Era" (Comisión Europea, 2010c), y, un año después, otra recomendación (aún vigente) sobre la digitalización y la accesibilidad en línea del material cultural y la preservación digital - Recommendation on the digitisation and online accessibility of cultural material and digital preservation (Comisión Europea, 2011b) -, aplicable a la memoria cultural de Europa (incluido el patrimonio cinematográfico) y en la que se pide establecer objetivos cuantitativos claros para la digitalización del material cultural, en consonancia con los objetivos generales asignados a Europeana. Poco después, la Comisión Europea publicó en el mismo año un amplio estudio más específico sobre una agenda digital para el patrimonio cinematográfico europeo - Digital Agenda for European Film Heritage o DAEFH (Mazzanti, 2011), llevado a cabo por expertos independientes y en el que se alerta de las deficiencias, falta de financiación e inadaptación general por parte de las filmotecas en cuanto a la (costosa) preservación del cine digital (2011, p. 127133).

Otra de las grandes preocupaciones de la Comisión Europea, además de la cuestión de la digitalización (la cual ha venido controlando de manera directa desde 2012), ha sido lo relacionado con los derechos de autor. Acerca de esto último, se publicó en 2001 la "Directiva de la Unión Europea sobre derecho de autor" (Parlamento Europeo y Consejo Europeo, 2001), sobre la armonización de ciertos aspectos del derecho de autor y derechos relacionados en la sociedad de la información de la Unión Europea que se contemplan como excepciones a la misma: el artículo 5(2)(c), que permite a los países miembros autorizar actos de reproducciones hechas por archivos o librerías accesibles públicamente que no sean con fines comerciales directos o indirectos (excepción implementada en sus legislaciones nacionales de copyright por todos excepto Reino Unido y Bulgaria); el artículo 5(3)(n), que permite a los países miembros autorizar la consulta in situ para investigadores (adoptada por doce países miembros, entre ellos España); y, por último, el artículo 5(3)(a), que incluye una excepción voluntaria a la directiva, relativa al único fin de ilustración para la enseñanza o la investigación científica (aplicada en aquel momento por 11 países miembros, entre ellos España). Todos los demás usos requerirían consentimiento previo del propietario de los derechos.

En 2016 se publicó la propuesta de una nueva directiva sobre los derechos de autor en el mercado único digital (Comisión Europea, 2016), aún pendiente de aprobación, dadas las múltiples trabas e impedimentos que ha encontrado.

Respecto a esta cuestión de los derechos, el "Libro Verde sobre copyright en la economía del conocimiento" de 2008 - Copyright in the knowledge economy (Comisión Europea, 2008b) abrió una discusión en el rango de las excepciones. Y es que los archivos cinematográficos expresaron que esas salvedades deberían ser obligatorias y su aplicación unificada entre los países miembros, así como que las mismas deberían ser también aplicadas al mundo digital. En 2009, la comunicación de la comisión sobre "Copyright in the knowledge economy" (Comisión Europea, 2009) no aportó nada nuevo al respecto. Y en Julio de 2011, la comisión continuó la discusión en el último "Libro Verde sobre la distribución en línea de los trabajos audiovisuales en la Unión Europea” (Comisión Europea, 2011a).

Por otro lado, en 2013, en la "Comunicación de la Comisión Europea sobre la ayuda estatal a las obras cinematográficas y otras producciones del sector audiovisual”, se incorpora la protección de los documentos fílmicos y el acceso a estos, insistiendo a los Estados en la necesidad de depositarse en sus filmotecas nacionales copias de las películas subvencionadas - proponiéndose incluso para ello el abono del último tramo de la ayuda una vez realizado tal depósito - y de permitirse determinados usos no comerciales de las mismas (Comisión Europea, 2013, p. 4 y 8).

Desde entonces, la Comisión Europea ha venido estableciendo un diálogo con las partes interesadas sobre determinadas cuestiones de carácter urgente, sobre todo en el asunto relativo a los derechos de autor, además de los problemas relativos a la conservación y la disponibilidad en línea de catálogos y colecciones digitalizadas de documentos fílmicos. No obstante, el Grupo de Expertos en Patrimonio Cinematográfico constituido en la Unión Europea, que celebró reuniones en 2012, 2013 y 2014, no ha vuelto a reunirse desde ese último año. Ello, unido al hecho de que no se han publicado tampoco desde ese año nuevos informes bianuales de implementación de las Recomendaciones de 2005, nos lleva con cierta preocupación a deducir que se ha producido un cierto freno a la intervención de los organismos públicos en materia de documentación fílmica en los últimos años. 


\section{CONCLUSIONES}

Los numerosos pronunciamientos oficiales enumerados en este trabajo sirven como evidencia de que, desde los años setenta del pasado siglo en adelante, los organismos públicos internacionales, especialmente europeos, como la Unesco, el Parlamento Europeo, el Consejo de Europa o la Comisión Europea han venido insistiendo a los Estados, las filmotecas y sus asociaciones o federaciones acerca de la importancia de una adecuada preservación, gestión documental y acceso al patrimonio cinematográfico. Y estos dictados, atendidos o desatendidos, han venido afectando y acompañando tanto a las políticas estatales como al trabajo diario de los documentalistas en las últimas décadas, constituyendo, por tanto, una parte muy importante de la historia de la documentación fílmica, la cual hemos querido dar a conocer y subrayar con la presente investigación. No obstante, a la vista de las deficiencias actuales en la materia, esta intervención oficial a nivel internacional sigue siendo necesaria, para que los Estados y sus archivos no se relajen y el patrimonio fílmico no se pierda.

\section{BIBLIOGRAFÍA}

AA.VV. Europeana [en línea]. Disponible en: <http://www.europeana.eu/portal/> [Consulta: 25 de marzo de 2019]

AA.VV. European Film Gateway [en línea]. Disponible en: $<$ http://www.europeanfilmgateway.eu/> [Consulta: 25 de marzo de 2019]

AA.VV. European Film Gateway 1914 [en línea]. Disponible en: < http://project.efg1914.eu/> [Consulta: 25 de marzo de 2019]

DOMÍNGUEZ-DELGADO, R. y LÓPEZ-HERNÁNDEZ, M.A. Análisis documental del contenido fílmico en seis filmotecas españolas. El profesional de la información, 2016, vol. 25, nº 5, p. 787-794.

DOMÍNGUEZ-DELGADO, R. y LÓPEZ-HERNÁNDEZ, M.A. La Documentación Fílmica: marco contextual histórico. Documentación de las Ciencias de la Información, 2016, nº 39, p. 13-49.

DOMÍNGUEZ-DELGADO, R. y LÓPEZ-HERNÁNDEZ, M.A. The retrieval of moving images at Spanish film archives: The oversight of content analysis. Proceedings of the Association for Information Science and Technology, 2016, vol. 53, $\mathrm{n}^{\mathrm{o}}$ 1, p. 1-4.

DOMÍNGUEZ-DELGADO, R. y LÓPEZ-HERNÁNDEZ, M.A. Una perspectiva histórica del análisis documental de contenido fílmico. Documentación de las Ciencias de la Información, 2017, nº 40, p. 73-90.

DOMÍNGUEZ-DELGADO, R. y LÓPEZ-HERNÁNDEZ, M.A. Film content analysis on FIAF cataloguing rules and CEN metadata standards. Proceedings of the Association for Information Science and Technology, 2017, vol. 54, $\mathrm{n}^{\mathrm{o}} 1$, p. 655-657.

BORDE, R. Los Archivos Cinematográficos. Valencia: Filmoteca de la Generalitat Valenciana, 1991.

BRITISH FILM INSTITUTE. BFI Collection Policy. BFI, 16 de noviembre de 2011 [en línea]. Disponible en: $<$ http://bfi.org.uk/sites/bfi.org.uk/files/downloads/bfi-collection-policy-2011-11-16.pdf > [Consulta: 15 de marzo de 2019]

COMISIÓN EUROPEA. COM(2001) 534 final. Bruselas: Comisión Europea, 26 de septiembre de 2001 [en línea]. Disponible en: <http://ec.europa.eu/transparency/regdoc/rep/1/2001/EN/1-2001-534-EN-F1-1.Pdf> [Consulta: 22 de febrero de 2019]

COMISIÓN EUROPEA. 2006/585/EC. Bruselas: Comisión Europea, 24 de agosto de 2006 [en línea]. Disponible en: $<$ https://eur-lex.europa.eu/LexUriServ/LexUriServ.do?uri=OJ:L:2006:236:0028:0030:EN:PDF> [Consulta: 25 de febrero de 2019]

COMISIÓN EUROPEA. COM(2007) 833 final. Bruselas: Comisión Europea, 20 de diciembre de 2007 [en línea]. Disponible en: <https://eur-lex.europa.eu/LexUriServ/LexUriServ.do?uri=COM:2007:0833:FIN:EN:PDF> [Consulta: 25 de febrero de 2019]

COMISIÓN EUROPEA. COM(2007) 836 final. Bruselas: Comisión Europea, 3 de enero de 2008a [en línea]. Disponible en: <https://eur-lex.europa.eu/LexUriServ/LexUriServ.do?uri=COM:2007:0836:FIN:EN:PDF> [Consulta: 25 de febrero de 2019]

COMISIÓN EUROPEA. COM(2008) 466. Bruselas: Comisión Europea, 16 de julio de $2008 b$ [en línea]. Disponible en: <https://eur-lex.europa.eu/LexUriServ/LexUriServ.do?uri=COM:2008:0466:FIN:EN:PDF> [Consulta: 25 de febrero de 2019]

COMISIÓN EUROPEA. SEC(2008) 2373. Bruselas: Comisión Europea, 4 de agosto de 2008c [en línea]. Disponible en:

$<\mathrm{http}: / / 1$ seminariopreservacaopatrimoniodigital.dglab.gov.pt/wpcontent/uploads/sites/19/2015/08/recurso_05.pdf> [Consulta: 25 de febrero de 2019]

COMISIÓN EUROPEA. COM(2009) 532. Bruselas: Comisión Europea, 19 de octubre de 2009 [en línea]. Disponible en: <https://eur-lex.europa.eu/LexUriServ/LexUriServ.do?uri=COM:2009:0532:FIN:EN:PDF> [Consulta: 5 de marzo de 2019] 
COMISIÓN EUROPEA. COM(2010) 245. Bruselas: Comisión Europea, 19 de mayo de 2010a [en línea]. Disponible en: <https://eur-lex.europa.eu/LexUriServ/LexUriServ.do?uri=COM:2010:0245:FIN:ES:PDF> [Consulta: 5 de marzo de 2019]

COMISIÓN EUROPEA. SEC(2010) 853. Bruselas: Comisión Europea, 2 de julio de 2010b [en línea]. Disponible en: $<$ http://edz.bib.uni-mannheim.de/edz/pdf/sek/2010/sek-2010-0853-en.pdf> [Consulta: 5 de marzo de 2019]

COMISIÓN EUROPEA. COM(2010) 487 final. Bruselas: Comisión Europea, 24 de septiembre de 2010c [en línea]. Disponible en: <https://eur-lex.europa.eu/LexUriServ/LexUriServ.do?uri=COM:2010:0487:FIN:EN:PDF> [Consulta: 5 de marzo de 2019]

COMISIÓN EUROPEA. COM(2011) 427 final. Bruselas: Comisión Europea, 13 de julio de 2011a [en línea]. Disponible en: <https://eur-lex.europa.eu/LexUriServ/LexUriServ.do?uri=COM:2011:0427:FIN:ES:PDF> [Consulta: 14 de marzo de 2019]

COMISIÓN EUROPEA. Commission Recommendation of 27 October 2011 on the digitisation and online accessibility of cultural material and digital preservation. Diario Oficial de la Unión Europea, 29 de octubre de 2011b, p. 39-45 [en línea]. Disponible en: <https://eur-lex.europa.eu/legalcontent/ES/TXT/PDF/?uri=CELEX:32011H0711\&from=EN $>$ [Consulta: 14 de marzo de 2019]

COMISIÓN EUROPEA. SWD(2012) 431 final. Bruselas: Comisión Europea, 7 de diciembre de 2012 [en línea]. Disponible $<$ http://www.arhiv.gov.si/fileadmin/arhiv.gov.si/pageuploads/zakonodaja/Predpisi/Film_EU_2012_Report.pdf> [Consulta: 22 de marzo de 2019]

COMISIÓN EUROPEA. Comunicación de la Comisión sobre la ayuda estatal a las obras cinematográficas y otras producciones del sector audiovisual. Diario Oficial de la Unión Europea, C332, 15 de noviembre de 2013, p. 1-11 [en línea]. Disponible en: <https://eur-lex.europa.eu/legalcontent/ES/TXT/PDF/?uri=CELEX:52013XC1115(01)\&from=ES> [Consulta: 22 de marzo de 2019]

COMISIÓN EUROPEA. European Commission's Report on Film Heritage. Bruselas: Comisión Europea, 1 de octubre de 2014 [en línea]. Disponible en: <https://ec.europa.eu/digital-single-market/en/news/european-commissionsreport-film-heritage $>$ [Consulta: 23 de marzo de 2019]

COMISIÓN EUROPEA. COM(2016) 593 final. Bruselas: Comisión Europea, 14 de septiembre de 2016 [en línea]. Disponible en: <https://ec.europa.eu/transparency/regdoc/rep/1/2016/ES/1-2016-593-ES-F1-1.PDF> [Consulta: 23 de marzo de 2019]

CONSEJO DE EUROPA. Recomendación sobre la Conservación del Patrimonio Cinematográfico Europeo. Recomendación R (85) 8, 14 de mayo de 1985.

CONSEJO DE EUROPA. Decisión 90/685/CEE. Diario Oficial de la Unión Europea, L380, 31 de diciembre de 1990, p. 37-44 [en línea]. Disponible en: <https://publications.europa.eu/en/publication-detail/-/publication/ee70f7d588b2-4bb6-a4d3-> [Consulta: 1 de febrero de 2019]

CONSEJO DE EUROPA. Resolución del Consejo 2000/C 193/01. Diario Oficial de las Comunidades Europeas, C 193, 11 de julio de 2000a, p. 1-2 [en línea]. Disponible en: <https://eur-lex.europa.eu/legalcontent/ES/TXT/PDF/?uri=CELEX:32000Y0711(01)\&from=ES $>$ [Consulta: 18 de febrero de 2019]

CONSEJO DE EUROPA. Decisión 2000/821/CE. Diario Oficial de las Comunidades Europeas, L336, 30 de diciembre de 2000b, p. 82-91 [en línea]. Disponible en: <https://eur-lex.europa.eu/legalcontent/ES/TXT/PDF/?uri=CELEX:32000D0821\&from=ES299abb7778 41/language-es $>$ [Consulta: 18 de febrero de 2019]

CONSEJO DE EUROPA. Decisión 2001/48/CE. Diario Oficial de la Unión Europea, L14, 18 de enero de $2001 \mathrm{a}$, p. 32-40 [en línea]. Disponible en: <https://publications.europa.eu/es/publication-detail/-/publication/6593e7b4-4f0f4165-abfa-01 ea35e20d02/language-es $>$ [Consulta: 22 de febrero de 2019]

CONSEJO DE EUROPA. European Treaty Series - No. 183 European Convention for the Protection of the Audiovisual Heritage. Consejo Europeo: Estrasburgo, 8 de noviembre de 2001b [en línea]. Disponible en: $<$ https:/www.coe.int/en/web/conventions/full-list/-/conventions/treaty/183> [Consulta: 22 de febrero de 2019]

DE FONTECHA, R. Un laboratorio para salvar el legado del cine. El Confidencial, 12 de agosto de 2014 [en línea]. Disponible en: <http://www.elconfidencial.com/cultura/2014-08-12/un-laboratorio-para-salvar-el-patrimoniocinematografico-espanol_174967/> [Consulta: 23 de marzo de 2019]

DEUTSCHES FILMINSTITUT (coord.). Filmarchives Online [en línea]. Disponible en: <http://www.filmarchivesonline.eu/> [Consulta: 17 de marzo de 2019]

EDMONDSON, R. Memoria del Mundo: Directrices para la Salvaguarda del Patrimonio Documental. París: Unesco, 1995 [en línea]. Disponible en: $<$ https://unesdoc.unesco.org/ark:/48223/pf0000125637_spa?posInSet=6\&queryId=N-EXPLORE-f2f1e9ae-30944986-8654-648eac70b71a> [Consulta: 4 de febrero de 2019]

FEDERACIÓN INTERNACIONAL DE ARCHIVOS FÍLMICOS (FIAF). Reglas de Catalogación de la FIAF para Archivos Fílmicos. México D.F: Archivo General de Puerto Rico, Filmoteca de la UNAM, 1998. 
KOFLER, B. Cuestiones Jurídicas Relacionadas con los Archivos Audiovisuales. PGI-91/WS/5. París: Unesco, 1991 [en línea]. Disponible en: <https://unesdoc.unesco.org/ark:/48223/pf0000088674_spa > [Consulta: 1 de febrero de 2019]

KOHTE, W. Archives of Motion Pictures, Photographic Records, and Sound Recordings: Report at the 7th International Congress on Archives. París, 1972.

KULA, S. La evaluación de las imágenes en movimiento de los archivos: un estudio del RAMP con directrices. París: Unesco, 1983 [en línea]. Disponible en: <https://unesdoc.unesco.org/ark:/48223/pf0000057669_spa> [Consulta: 29 de enero de 2019]

KROES, N. Commission Report Finds One Million Hours of European Film Locked Away in Cans \& Cupboards. Comisión Europea, 20 de diciembre de 2012 [en línea]. Disponible en: <http://europa.eu/rapid/press-release_IP12-1427_en.htm> [Consulta: 20 de marzo de 2019]

HERNÁNDEZZ PÉREZ, A. Documentación audiovisual. Metodología para el análisis documental de la información periodistica audiovisual. Madrid: Universidad Complutense, 1992.

MAZZANTI, N. (ed.). Digital Agenda for European Film Heritage. Challenges of the Digital Era for Film Heritage Institutions. Berlín: Unión Europea, 2011 [en línea]. Disponible en: <http://www.ace-film.eu/wpcontent/uploads/2012/05/final_report_en.pdf $>$ [Consulta: 15 de marzo de 2019]

PARLAMENTO EUROPEO. Enmienda 54, Enmienda 65 y Enmienda 66. PE 362.412v02-00. Enmiendas 38-70, 12 de septiembre de 2005, p. 8-9, 13 y 14 [en línea]. Disponible en: $<$ http://www.europarl.europa.eu/meetdocs/2004_2009/documents/am/577/577051/577051et.pdf> [Consulta: 23 de febrero de 2019]

PARLAMENTO EUROPEO y CONSEJO DE LA UNIÓN EUROPEA. Directiva 2001/29/CE. Diario Oficial de las Comunidades Europeas, L167, 22 de junio de 2001, p. 10-19 [en línea]. Disponible en: <https://eurlex.europa.eu/legal-content/ES/TXT/PDF/?uri=CELEX:32001L0029\&from=ES> [Consulta: 22 de febrero de 2019]

PARLAMENTO EUROPEO y CONSEJO DE LA UNIÓN EUROPEA. Resolución COM(2001) 534 - C50078/2002 - 2002/2035(COS). Diario Oficial de la Unión Europea, C271E, 12 de noviembre de 2003, p. 176-180 [en línea]. Disponible en: <https://eur-lex.europa.eu/legalcontent/ES/TXT/PDF/?uri=CELEX:52002IP0347\&from=ES> [Consulta: 22 de febrero de 2019]

PARLAMENTO EUROPEO y CONSEJO DE LA UNIÓN EUROPEA. Propuesta de Recomendación del Parlamento Europeo y del Consejo relativa al patrimonio cinematográfico y la competitividad de las actividades industriales relacionadas. Diario Oficial de la Unión Europea, 30 de abril de 2004, p. 4-7 [en línea]. Disponible en: $<$ https://eur-lex.europa.eu/resource.html?uri=cellar:1dcb0767-3355-45ed-944c79785e387078.0005.02/DOC_2\&format=PDF $>$ [Consulta: 23 de febrero de 2019]

PARLAMENTO EUROPEO y CONSEJO DE LA UNIÓN EUROPEA. Decisión 456/2005/CE. Diario Oficial de la Unión Europea, L79, 24 de marzo de 2005a, p. 1-8 [en línea]. Disponible en: <https://eur-lex.europa.eu/legalcontent/ES/TXT/PDF/?uri=CELEX:32005D0456\&from=ES $>$ [Consulta: 23 de febrero de 2019]

PARLAMENTO EUROPEO y CONSEJO DE LA UNIÓN EUROPEA. Recomendación 2005/865/CE. Diario Oficial de la Unión Europea, 9 de diciembre de 2005b, p. 57-61 [en línea]. Disponible en: <https://eur-lex.europa.eu/legalcontent/ES/TXT/PDF/?uri=CELEX:32005H0865\&from=EN $>$ [Consulta: 23 de febrero de 2019]

PARLAMENTO EUROPEO y CONSEJO DE LA UNIÓN EUROPEA. Decisión 1718/2006/CE. Diario Oficial de la Unión Europea, L 327, 24 de noviembre de 2006, p. 12-29 [en línea]. Disponible en: <https://eurlex.europa.eu/legal-content/ES/TXT/PDF/?uri=CELEX:32006D1718\&from=ES> [Consulta: 25 de febrero de 2019]

PARLAMENTO EUROPEO y CONSEJO DE LA UNIÓN EUROPEA. Reglamento (UE) $n^{\circ}$ 1295/2013. Diario Oficial de la Unión Europea, 20 de diciembre de 2013, p. 221-237 [en línea]. Disponible en: <https:/eurlex.europa.eu/legal-content/ES/TXT/PDF/?uri=CELEX:32013R1295\&from=ES> [Consulta: 23 de marzo de 2019]

PARLAMENTO EUROPEO y CONSEJO DE LA UNIÓN EUROPEA. Propuesta de Reglamento del Parlamento Europeo y del Consejo por el que se establece el programa Europa Creativa (2021 a 2027) y por el que se deroga el Reglamento (UE) n. ${ }^{\circ}$ 1295/2013. Parlamento Europeo y Consejo de la Unión Europea, 30 de mayo de 2018 [en línea]. Disponible en: <https:/eur-lex.europa.eu/resource.html?uri=cellar:509e1bcb-63f0-11e8-ab9c01aa75ed71a1.0010.02/DOC_1\&format=PDF $>$ [Consulta: 24 de marzo de 2019]

UNESCO. Actas de la Conferencia General. 18 a reunión. Volumen 1. Resoluciones. París: Unesco, 1975 [en línea]. Disponible en: <https://unesdoc.unesco.org/ark:/48223/pf0000114040_spa> [Consulta: 26 de enero de 2019]

UNESCO. Final Report of the Consultation of Experts on the Development of Audiovisual Archives, Viena, 10-12 abril 1984. París: Unesco, 1985 [en línea]. Disponible en: <https://unesdoc.unesco.org/ark:/48223/pf0000067851> [Consulta: 28 de enero de 2019]

UNESCO. Memoria del Mundo: Directrices para la salvaguarda del patrimonio documental. París: Unesco, 1995a [en línea]. Disponible en: <https://unesdoc.unesco.org/ark:/48223/pf0000105132> [Consulta: 4 de febrero de 2019] 
UNESCO. Actas de la $146^{a}$ Reunión del Consejo Ejecutivo. París: Unesco, 1995b [en línea]. Disponible en: $<$ https://unesdoc.unesco.org/ark:/48223/pf0000101253_spa> [Consulta: 4 de febrero de 2019]

UNESCO. Memoria del Mundo: Patrimonio cinematográfico nacional (CII-95/WS/7). París: Unesco, 1995c [en línea]. Disponible en: <https://unesdoc.unesco.org/ark:/48223/pf0000110379_spa > [Consulta: 4 de febrero de 2019]

UNESCO. Resolución 53. Actas de la 33a Conferencia General. Volumen 1. Resoluciones. París: Unesco, 2005 , p. 119 [en línea]. Disponible en: <https://unesdoc.unesco.org/ark:/48223/pf0000142825_spa.nameddest=81> [Consulta: 23 de febrero de 2019] 